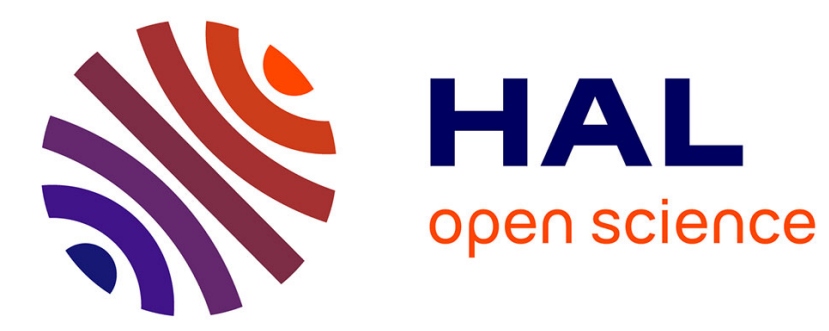

\title{
The medical doctors as gatekeepers in the sickness insurance?
}

Per Johansson

\section{To cite this version:}

Per Johansson. The medical doctors as gatekeepers in the sickness insurance?. Applied Economics, 2011, 10.1080/00036846.2011.579064 . hal-00711455

\section{HAL Id: hal-00711455 \\ https://hal.science/hal-00711455}

Submitted on 25 Jun 2012

HAL is a multi-disciplinary open access archive for the deposit and dissemination of scientific research documents, whether they are published or not. The documents may come from teaching and research institutions in France or abroad, or from public or private research centers.
L'archive ouverte pluridisciplinaire HAL, est destinée au dépôt et à la diffusion de documents scientifiques de niveau recherche, publiés ou non, émanant des établissements d'enseignement et de recherche français ou étrangers, des laboratoires publics ou privés. 


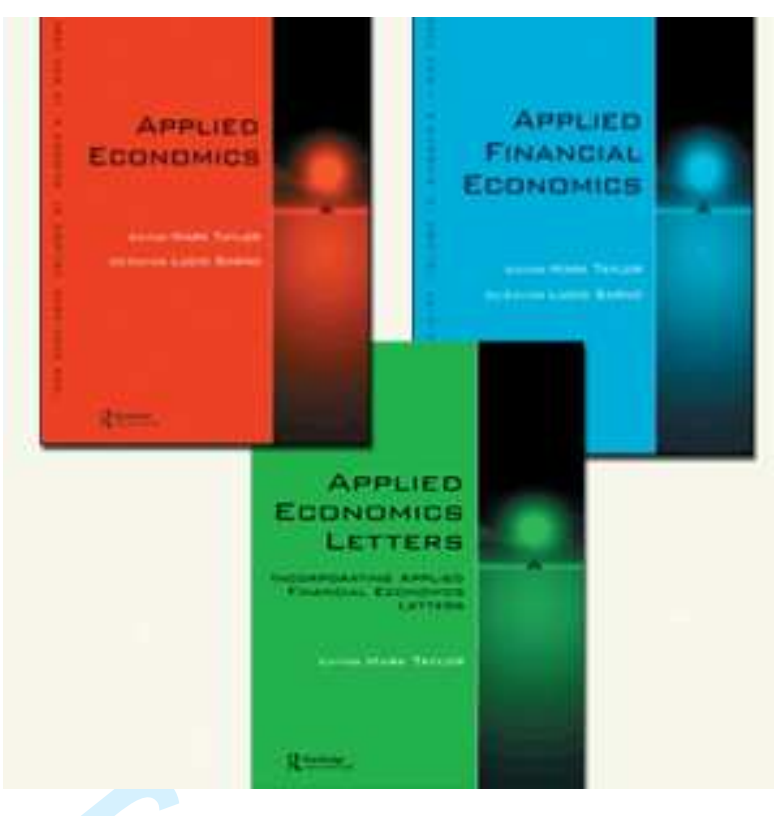

\section{The medical doctors as gatekeepers in the sickness insurance?}

\begin{tabular}{|r|l|}
\hline Journal: & Applied Economics \\
\hline Manuscript ID: & APE-2009-0427.R1 \\
\hline Journal Selection: & Applied Economics \\
\hline Date Submitted by the \\
Author: & 22-Sep-2010 \\
\hline Complete List of Authors: & Johansson, Per; IFAU, IFAU; Department of economics \\
\hline JEL Code: & $\begin{array}{l}\text { C93 - Field Experiments < C9 - Design of Experiments < C - } \\
\text { Mathematical and Quantitative Methods, H51 - Government } \\
\text { Expenditures and Health < H5 - National Government Expenditures } \\
\text { and Related Policies < H - Public Economics, H55 - Social Security } \\
\text { and Public Pensions < H5 - National Government Expenditures and } \\
\text { Related Policies < H - Public Economics, J22 - Time Allocation and } \\
\text { Labor Supply < J2 - Time Allocation, Work Behavior, and } \\
\text { Employment Determination/Creation < J - Labor and Demographic } \\
\text { Economics }\end{array}$ \\
\hline Keywords: & \begin{tabular}{l} 
monitoring, moral hazard, public social insurance \\
\hline
\end{tabular} \\
\hline
\end{tabular}




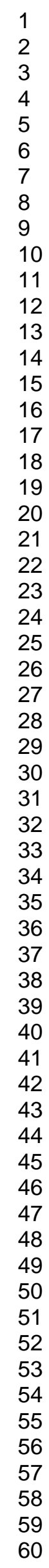

\section{SCHOLARONE ${ }^{m}$ \\ Manuscripts}

7

25

26

27

29

30

31

33

34

35

36

37

38

41

42

43

45

46

47

48

49

51

52

53

54

55

57

58

59

60 


\title{
The medical doctors as gatekeepers in the sickness insurance?*
}

by

Per Engström and Per Johansson

2010-09-21

\begin{abstract}
Based on a randomised experiment we estimate effects from notification to medical doctors of tighter monitoring of their medical certificates. Both time prescribed by the doctor certificates for sick leave (prescribed sick leave) and the impact on the length of the actual sickness absence (actual sick leave) is studied. We find no effect on the total number of prescribed sick leave days. We do, however, find an increase in both prescribed and actual sick leave with a 25 percent work inability. We also find that the notification letter causes an increase in actual sick leave (i.e. the number of reimbursed sick days). We discuss a number of potential explanations for this rather surprising result.
\end{abstract}

\footnotetext{
* The authors would like to thank Hans Goine, Erik Grönqvist, Patrik Hesselius, Edward Palmer, Peter Skogman Thoursie, Patric Tirmén, Ingeborg Wernbaum, seminar participants from the presentation at IFAU, the Swedish Social Insurance Agency, the Swedish Ministry of Social Welfare and the Swedish Economic History Meeting 2009. We would also like to thank Niklas Österlund for technical assistance in designing the databases. The financial support of the Swedish Council for Working Life and Social Research FAS (dnr 2004-2005 and 2007-0122) is acknowledged
} 


\footnotetext{
${ }^{1}$ Previous studies show that, among others, financial incentives (e.g., Johansson \& Palme, 1996; 2002; 2005 and Henrekson \& Persson, 2004), norms (e.g., Lindbeck et al., 2007; Hesselius et $a l ., 2009$ and Palmer, 2006) and control or monitoring of the incapacity for work of those on sick leave (e.g. Hesselius et al., 2006 and Lindahl, 2008) are important for the level of sickness absence.

${ }^{2}$ The notification letter was also sent to centres for primary health care, but for simplicity, the term medical centre is used to describe both medical centres and centres for primary health care.
} 
however, that the number of days of sickness benefit increases - both gross and net. $^{3}$

The SSIA has no sanctions against doctors who write flawed medical certificates so the letter can be seen as a plea for better quality. From this perspective, this action (sending of the letter) could be seen as a relatively small change in a doctor's incentive to issue good quality medical certificates. That this action would have little or no impact was seen as a possible outcome. But that sickness absence would increase as a result of sending out the letter is a surprising result.

Goine et al. (2009) study the quality of the medical certificates on a subsample of our sample. ${ }^{4}$ The results of this parallel study show that the quality of the medical certificates is reduced as a result of sending out the notification letters about tightened monitoring. A potential explanation for the results we report here might be that deterioration in the quality of the medical certificates prolongs sick leave. A decrease in quality increases the likelihood that the medical certificate is referred back to the doctor, which prolongs sick leave (Johansson and Nilsson, 2008). However, according to the analysis in our study, an increased referral back to the doctor cannot totally explain the increase in sick leave. The report discusses why the quality of the supporting medical certificate deteriorates as a result of the notification letter and alternative explanations for the observed increase in sick leave.

The report is set out as follows: Section 2 describes the conditions that apply to social insurance in Sweden and the sick-leave process. In section 3 we describe the randomised experiment. Section 4 describes the data we use to implement the analysis presented in Section 5. Section 6 consists of a discussion and further analysis of the results in Section 5. The report concludes with a summary and discussions in Section 7.

\section{Sick leave in Sweden}

Sickness insurance replaces income for individuals who cannot perform their usual work because of temporary illness. The level of sickness benefit and the employer's liability for sick pay has fluctuated in recent years. At the time of

\footnotetext{
${ }^{3}$ The difference between gross and net is that the gross measure counts a day of sick leave regardless of the degree of work inability, while the net measure means that a day of sick leave with a 25 per cent work inability is measured as a quarter of a day.

${ }^{4}$ Quality assessment was undertaken by two experienced insurance doctors.
} 
the study, employer's pay sick pay equivalent to 80 per cent of the worker's previous salary subject to a ceiling of 601 SEK per day during days 2-14 of the period of sick leave (SSIA, 2007). After this period the responsibility for sick pay transfers to the SSIA.

During the first seven days of a sick leave, it is, in practice, up to the individual to decide whether (s)he is ill and the extent to which this warrants absence from work. The individual merely has to inform the employer or the SSIA that they are ill. As of the eighth day a medical certificate is required. For sick leave that continues for longer than two weeks the employer notifies the SSIA that sick leave is continuing. The SSIA sends a letter to the insured with a form and a request for a medical certificate. A medical certificate is needed for entitlement to continued payment of sickness insurance. The doctor indicates in the medical certificate the length and extent of the sick leave that (s)he believes the insured needs to have. Based on the medical certificate the SSIA determines the right to sick leave, a process that normally takes at least one to two weeks after the end of the employer period. When this first sick leave period with benefit from the SSIA has expired, if necessary, a renewal certificate is issued. The renewal certificate is also sent to the SSIA and a new assessment about the right to sickness benefits is made. When the renewal certificate expires and the insured is still sick, the process is repeated.

Based on the information in the medical certificate the SSIA decides whether the illness causes reduced capacity for work (i.e. work inability). For those who have a job, the work inability is based primarily in relation to the current job. For those who are unemployed is work inability assessed against jobs ordinarily available in the labour market. The proportion of cases where the SSIA decides contrary to the doctor's recommendation is, however, small. During 2006 the request for sick pay was rejected in 1.5 per cent of all new cases (SSIA, 2007). The percentage of rejections increased to 1.7 per cent in 2008 and the proportion of revocations of sickness benefit is stable at 1 per cent.

To help to assess entitlement to sickness benefit a guide has been published: Försäkringskassan Vägledning 2004:2, "Sickness benefit and coordinated rehabilitation" (SSIA, 2004). The document describes what information must be included in the medical certificate in order to assess entitlement to sick pay and the need for rehabilitation. The SSIA makes use of a so-called support method in working with sick leave. The support method makes a distinction between information that is "mandatory" and that, which is 
"desirable" in the medical certificate. In cases where the SSIA officials do not believe that the medical certificate contains sufficient information, they have the opportunity to refer the certificate back to the doctor for completion.

Mandatory information according to SSIA (2004) are: the patient's name and social security number, the doctor's name and clinic/office hours, diagnosis or symptoms that are the basis for the work inability and the diagnosis code according to ICD-10 $10^{5}$. In addition there should be a description and medical assessment of the work inability. The doctor must also indicate findings from their examination in support of the diagnosis and the requirement for vocational rehabilitation, if any. The medical certificate must also state whether the doctor's information is based on personal contact, telephone contact, journal entries or other sources ${ }^{6}$. The doctor should also give reasons why parttime sick leave (i.e. 25 per cent, 50 per cent or 75 per cent work inability) and/or workplace rehabilitation is not possible. Finally, there should be a prognosis as to the insured's potential for regaining the capacity to work. Included under "desirable" information are such things as case history, i.e. the insured's description of the illness and events that might have caused it (SSIA, 2004).

In this study we distinguish between the prescribed sick leave and the actual sick leave. The former is the period that the doctor has recommended in the medical certificate and the latter the actual time that the individual was absent from work and receiving benefit from SSIA due to illness.

There are two reasons for why the measures may differ. The first reason is that there are no impediments to return to work before the end of a prescribed sick leave period (leading to a shorter actual absence then prescribed). The second reason has to do with renewal certificates and sampling. In the context of the experiment, we collect certificates issued in August and September 2007. The individual's actual sickness absence is recovered from register information with the last information on sickness absence in April 17 2008. Naturally, a renewed medical certificate for a medical certificate sampled in September can be issued. Since the renewed medical certificate may be issued after the sample period, the actual absence may continue much longer than the sampled certificates prescribe.

5 ICD-10 stands for "International statistical classification of diseases and related health problems, Tenth Revision 2" and is the WHO's classification system for different disease diagnoses (Socialstyrelsen, 1995).

${ }^{6}$ Examples of "other" is a psychiatrist that grants sick leave on the recommendation of the care team that manages the treatment. This can also happen in substance abuse cases. 


\section{The experiment}

The experiment was carried out at the municipality level. As sickness absence varies across different parts of Sweden the SSIA selected the median populated municipality in each county except Gotland ${ }^{7}$ and the municipality closest to this median. These two municipalities were then assigned at random: one to be the treatment municipality (i.e. receiving the notification letter) and one the control municipality.

The letter (see the Appendix) indicated that for a period of time (the sample period: $27^{\text {th }}$ August 2007 to $30^{\text {th }}$ September 2007) the SSIA would increase monitoring and control of the quality of their medical certificates. This increase in monitoring was implemented in the same way in the treatment and the control municipalities. The SSIA officials hence received the same instructions for both types of municipalities. They were also uninformed of which municipalities were treated. This gives us the opportunity to interpret any differences between the municipalities as a result of the letter itself and not as effects of increased monitoring per se.

\subsection{Validity of the experiment}

There are only 20 treatment and control municipalities. This implies that, despite the stratification, there may be some differences between the two groups just by chance, which may bias the estimated effects. In order to study if this is, indeed, a problem we present the average sick leave in the municipalities before the experiment was conducted (see Table 1). The average sick leave is based on payment data from the SSIA. The historical sickness leave is calculated by taking all the sickness benefit days from 1 January 2005 until 26 August 2007 and then dividing these by the number of people enrolled in the municipality's social insurance fund (everyone between 16 and 64 years of age). ${ }^{8}$ This provides a measure of the occurrence of sick leave, or prevalence. From the table we can see that the historical figure for sick leave is slightly higher among people living in the municipalities that receive the letter than among those who live in municipalities that do not receive the letter.

\footnotetext{
${ }^{7}$ Gotland is both a municipality and county and is therefore not represented in the study. The municipalities were chosen to be as close to the average municipality in the county as possible.

${ }^{8}$ I.e. (net benefit days from the 1 January 2005 up to and including 26 August 2007)/(number of individuals aged 16-64).
} 
However, the difference is not statistically significant at any reasonable level of risk.

Table 1: Historical sick leave.

\begin{tabular}{lccc}
\hline Municipality & Historical sick leave & 95\% confidence interval & $\begin{array}{c}\text { t-test } \\
\text { (p-value) }\end{array}$ \\
\hline Treatment & 31.34 & $(30.4575 \leftrightarrow 34.4319)$ & 0.77 \\
Control & 32.44 & $(29.3917 \leftrightarrow 33.2952)$ & $(0.44)$ \\
\hline $\begin{array}{l}\text { Notes: Historical sick leave is the average number of net days with sickness benefit per person during the } \\
\text { historical period. The historical period is defined as 1 January 2005 until 26 August 2007; t-test tests for the } \\
\text { mean differences between groups. }\end{array}$
\end{tabular}

\section{$4 \quad$ Data and description}

The staff at the SSIA submitted the medical certificates that were issued during the sample period to the head office (both extensions of old sickness and a new sickness). From these medical certificates we have information on, among other things, the period of sick leave recommended by the doctor (i.e. prescribed sick leave), the diagnosis and the gender of the doctor.

The total number of submitted medical certificates is 2,808 (2,299 individuals), of which 1,503 (1,195 individuals) originate from a medical centre that received the letter. In the situation of multiple medical certificates for the same individual only the fist is included in the study. From the SSIA's sickness records, we match the data including the number of days an individual receives benefits. This means that 58 individuals are excluded. The final analysis material consists of 2,241 individuals (1,166 from treatment municipalities). Table 2 summarizes the selections made.

Table 2 : Number of medical certificates (MCs) and persons included in the study

\begin{tabular}{ccccc}
\hline Group & $\begin{array}{c}\text { Number of } \\
\text { MCs }\end{array}$ & $\begin{array}{c}\text { Number of } \\
\text { individuals }\end{array}$ & $\begin{array}{c}\text { Unable to } \\
\text { match }\end{array}$ & $\begin{array}{c}\text { Total no. of } \\
\text { individuals }\end{array}$ \\
\hline Treatment & 1,503 & 1,195 & 29 & 1,166 \\
Control & 1,305 & 1,104 & 29 & 1,075 \\
Total & 2,808 & 2,299 & 58 & 2,241 \\
\hline
\end{tabular}




\subsection{Sample selection problems}

Based on register information on paid sickness benefit, we calculate ${ }^{9}$ that only about half of all the medical certificates are received. This sample selection is problematic if the selection criteria for sending in the medical certificates differ between the control and treatment municipalities.

Table 2 show that the number of certificates submitted is very similar in the two groups. Since the two municipalities were selected on population size, it seems that the share of medical certificates is not dependent on treatment status. From the calculations (for details see footnote 9) we do not either find that the sample selection differs between the two groups. Hence, we interpret any difference in outcomes between the treatment and control groups as caused by the treatment (the letter).

Table 3 : Average, standard deviations (st.dev.) and test (t-test) for the mean differences of background variables.

\begin{tabular}{|c|c|c|c|c|c|}
\hline Variable & \multicolumn{2}{|c|}{ Control } & \multicolumn{2}{|c|}{ Treatment } & t-test \\
\hline & average & st.dev. & average & st.dev. & \\
\hline Proportion males & 0.35 & 0.48 & 0.36 & 0.48 & $\begin{array}{c}0.40 \\
(0.69)\end{array}$ \\
\hline Age & 47.44 & 11.26 & 47.53 & 10.66 & $\begin{array}{c}0.19 \\
(0.85)\end{array}$ \\
\hline $\begin{array}{l}\text { Proportion with secondary } \\
\text { education }\end{array}$ & 0.62 & 0.49 & 0.59 & 0.49 & $\begin{array}{l}-1.54 \\
(0.12)\end{array}$ \\
\hline $\begin{array}{l}\text { Proportion with tertiary } \\
\text { education. }\end{array}$ & 0.16 & 0.37 & 0.18 & 0.38 & $\begin{array}{c}1.04 \\
(0.30)\end{array}$ \\
\hline Historical sick leave & 252.01 & 266.71 & 270.34 & 275.92 & $\begin{array}{c}1.59 \\
(0.11)\end{array}$ \\
\hline
\end{tabular}

Note: Historical sick leave relates to how many net days the individual received sickness benefit during the period 1 January 2005 - 26 August 2007. The variable is calculated from net sick leave, i.e. 25 per cent sickness benefit for four days is counted as one day with 100 per cent sickness benefit.

\footnotetext{
${ }^{9}$ This calculation is based on four assumptions: (1) that sick leave and the issuing of medical certificates is constant over time; (2) that each certificate corresponds to the actual sickness benefit (we therefore disregarded the fact that there are sometimes medical certificates that refer to the sick pay period and also that not everyone takes sickness benefit for the whole time period to which it relates); (3) that there is no "overlap" of medical certificates - i.e. a certificate prescribed for a period (e.g. 10 October until 20 October) despite the fact that the individual had already received a certificate for an earlier period (e.g. 1 October until 15 October) and (4) that half of all medical certificates are granted by the health centres.
} 
Table 3 shows descriptive statistics separately for the treatment and control group. From the table it can be seen that there are no statistically significant differences in mean values between the two groups (p-value $<0.10$ ). We can also see that the two groups are almost identical in terms of males and age (see both the mean and standard deviation). When we compare the level of education, we find that the treatment group has a slightly lower proportion with secondary education and a slightly higher proportion with tertiary education. Individuals in the treatment group have a slightly higher historical sick leave on average than the control group. On the other hand, there is a lower variation in sick leave in the treatment group than in the control group. When we studied the average of the whole population (see Table 1) the treatment municipalities also showed a slightly higher sick leave than the control municipalities. Note that the average sick leave for our sample is more than ten times greater than that of an average individual. This is not surprising given that oversample i) sick leave spells are often very long and ii) sick leave varies greatly between individuals.

Another potential selection problem is that the experiment influenced who is on sick leave. That is, the experiment might cause doctors to refuse to issue medical certificates to their patients. In such scenario it is reasonable to assume that it is the less serious illnesses that get truncated. This means that as a direct result of the experiment, those on sick leave in the treatment municipalities are sicker on average than those who are on sick leave in the control municipalities. This in turn could lead to longer sick spells among individuals in the treatment municipalities than among individuals in the control municipalities.

We investigate whether there is an incidence effect using two different regression analyses. The result from these analyses is that the letter has no effect on the inflow into sick leave. ${ }^{10}$ Hence, the overall effect of the notification letter can be obtained by analysing the duration of the sick spells.

\subsection{Outcome variables}

Doctors can prescribe (recommend) full or part-time sick leave. When deemed possible, the doctor is encouraged by the SSIA to prescribe part-time sick leave since this is perceived to speed up the return to work. Consequently, the notification letter sent to the treatment municipalities is expected to affect not

\footnotetext{
${ }^{10}$ For details of the tests see http://ucls.nek.uu.se/working\%20papers/wp20104ucls.doc.pdf
} 
only the length of sick leave but also the degree of work inability $(25,50,75$ or 100 per cent). For this reason it is important to analyse the degree of prescribed and actual sick leave and not just the number of days with work inability, i.e. the gross number of days (prescribed/actual). We also define net (prescribed/actual) sick leave as the number of days an individual is not working, e.g. a work absence for four gross weeks with a 25 per cent work inability amounts to seven net days.

The effect of the intervention is estimated on both gross and net days. Furthermore, we estimate effects on both the prescribed sick leave (i.e. the prescribed work inability in the medical certificate), as well as the actual sick leave (i.e. days with benefits). If there are different effects on the gross and net variables, it means that the sick leave rate has changed. For example, if certificate gross is unchanged but certificate net decreases, the sick leave degree has decreased, which means that prescribed part-time sick leave has increased.

Our sample consists of individuals for whom we have medical certificates for the sickness that starts during the period of the experiment (new certificate), and for sickness that started before the experiment but for which there is renewed certificate during the experiment. ${ }^{11}$ All medical certificates and actual number of days of benefits (sick leave) that extend beyond 17 April 2008 are censored because we do not have actual sick leave data beyond that date. There are only 14 cases ( 0.6 per cent) where medical certificates are censored while for actual sick leave 920 cases of 2,241 (40 per cent) are censored.

Table 4 reveals descriptive statistics for the prescribed and actual sick leave (gross/net) for the two groups separately, and a test (t-test) for whether there are mean differences. The censored cases are treated here as if they were closed when our data collection came to an end (17 April 2008).

In the table (row 1) we see that the prescribed number of net days is lower for those in the treatment municipalities. On the other hand, the number of prescribed days (see row 2) increased slightly. However, neither of these differences is statistically significant. If, instead, the actual sick leave is analysed, we find that the number of days of benefits (both gross and net) have increased for the treatment group. But only the difference in the gross number of days (see row 4) is statistically significant. The interpretation is that the treatment has increased the gross spell length by about 9 days on average (142$133=9)$.

\footnotetext{
${ }^{11}$ The definition of a renewal certificate is based on the SSIA official's assessment.
} 
Table 4 : Average number of prescribed days (certificate gross/net) and average number of actual days absent (actual gross/net) for treatment and control.

\begin{tabular}{lcrr}
\hline Variable & \multicolumn{1}{c}{ Control } & Treatment & \multicolumn{1}{c}{ t-test } \\
\hline Certificate net & $42.76(0.98)$ & $41.99(1.00)$ & -0.55 \\
Certificate gross & $53.06(1.13)$ & $54.72(1.17)$ & 1.03 \\
Actual net & $107.23(1.13)$ & $111.13(2.44)$ & 1.11 \\
Actual gross & $133.14(2.66)$ & $142.09(2.58)$ & 2.41 \\
Number of observations & 1,075 & 1,166 & \\
\hline
\end{tabular}

Notes. Censored spells are treated as if they ended in 17 April 2008 (i.e. the end of study). Standard errors within parentheses. T-test is a test of differences in mean between the two groups.

Since the SSIA is looking to reduce the proportion of people on full time sick leave, it is interesting to study if there is any effect on the degree of work inability. Table 5 shows the average number of days with 25, 50, 75 and 100 per cent degree of work inability for the two groups separately, and a test (ttest) for whether there are differences in the average for each sick leave degree. ${ }^{12}$

Table 5 : Average prescribed and actual sick leave conditional on the degree of work inability for the treatment and control groups.

\begin{tabular}{crrr}
\hline Level & \multicolumn{1}{c}{ Control } & \multicolumn{1}{c}{ Treatment } & t-stat (p-value) \\
\hline \multicolumn{4}{c}{ Prescribed sick leave } \\
25 & $4.31(0.57)$ & $7.24(0.71)$ & $3.23(0.00)$ \\
50 & $12.89(0.92)$ & $12.78(0.90)$ & $-0.09(0.93)$ \\
75 & $2.50(0.37)$ & $3.65(0.55)$ & $1.73(0.08)$ \\
100 & $33.36(1.11)$ & $31.06(1.09)$ & $-1.48(0.14)$ \\
& Actual sick leave (register data) \\
25 & $12.27(1.11)$ & $17.90(1.41)$ & $3.14(0.00)$ \\
50 & $30.21(1.76)$ & $32.32(1.77)$ & $0.84(0.40)$ \\
75 & $7.27(0.84)$ & $8.34(0.95)$ & $0.85(0.40)$ \\
100 & $84.43(2.73)$ & $85.80(2.68)$ & $0.36(0.72)$ \\
\hline
\end{tabular}

Notes: standard errors within parenthesis. t-test (p-value within parenthesis) is a test of difference in means between the two groups.

From the table we can see that the average prescribed sick leave with 25 per cent work inability increases significantly (p-value $<0.01$ ). We also find an increase in the prescribed sick leave with 75 per cents work inability, but this is

\footnotetext{
${ }^{12}$ Again the censored cases are treated as if they were ended at the date of collection (17 April
} 2008). 
not statistically significant. The average number of days with 100 per cent prescribed work inability decreases slightly, but this effect is not statistically significant either.

We see the same pattern for the actual sick leave. There is a statistically significant (p-value $<0.01$ ) increase in sick leave with 25 per cent work inability, however here no compensatory reduction in full-time sick leave is seen.

There are at least two problems with the above analyses. The first is that the functional form may play a role, i.e. whether we are studying percentage differences or absolute differences may affect the statistical significance. ${ }^{13}$ The second problem (especially for actual sick leave) is that we did not take into consideration the fact that we have censored observations. Another thing to consider in the analysis is that we may increase the precision by controlling for historic sick leave.

In the following section, we study the effects of percentage changes (i.e. another functional form), taking into account censored cases and, in order to increase the accuracy of the estimates, we control for historic sick leave.

\section{Results}

The analyses are based on Cox proportional "hazard" regressions. In these regressions we estimate effects on conditional probability (hazard) that an ongoing prescribed and actual sick leave will end on a given day. ${ }^{14}$

The advantage of the Cox regression framework compared with ordinary least squares (OLS) framework is that the censored observations can easily be taken into account. There is a high proportion of censored observations in terms of the actual sick leave - 920 from a total of 2,148 cases. Not taking these into account lead to spurious results. With prescribed sick leave, we do not have the same problem with censoring - only 15 cases - so in this case, OLS of (log) linear regression models would be a good alternative. ${ }^{15}$

\footnotetext{
${ }^{13}$ The distribution of the number of days is right skewed. This means that most likely there would be better precision in the estimates if we study the percentage differences rather than the absolute differences.

${ }^{14} \mathrm{An}$ estimated treatment effect of e.g. 0.05 implies that the hazard rate for the treatment group is approximately 5 per cent higher than for the control group (the exact estimate of the proportional increase in the hazard is: $\mathrm{e}^{0.05}-1 \approx 0.05$ ).

${ }^{15}$ The results when treatment are regressed on the log of the duration where the censoring time is simply set to the end of study time are consistent with the results from the Cox regressions, while estimates of the actual sick leave are much less precisely estimated.
} 


\subsection{Prescribed sick leave}

Table 6 shows the effects of the experiment on the prescribed sick leave. In the table a positive impact means that the prescribed sick leave length is shorter for the treatment group. From the table we can see that when there are no control variables in the regression (columns (1) and (4)), the notification letter has no statistically significant effect on the prescribed sick leave, either net or gross days.

When we control for previous illness (columns (2 and 3) and (5 and 6)) the effect (a six percent reduction) on the net prescribed number of day is almost statistically significant ( $p$-value $<0.15$ ). The effect on the gross number of days is always very close to zero and not statistically significant.

Table 6 : Estimated effect (percentage) on the hazard from prescribed sick leave (gross and net).

\begin{tabular}{lrrrrrr}
\hline & $(1)$ & $\begin{array}{r}(2) \\
\text { Net }\end{array}$ & $(3)$ & $(4)$ & $\begin{array}{c}(5) \\
\text { Gross }\end{array}$ \\
\hline Effect & 0.027 & 0.061 & 0.066 & -0.040 & -0.003 & -0.008 \\
Standard error & 0.042 & 0.042 & 0.045 & 0.042 & 0.042 & 0.045 \\
(p-value) & 0.520 & 0.148 & 0.143 & 0.341 & 0.952 & 0.866 \\
Historical sick leave & No & Yes & Yes & No & Yes & Yes \\
Stratified on county & No & No & Yes & No & No & Yes \\
\hline
\end{tabular}

Note: Estimates of Cox regression models with "partial maximum likelihood" estimator.

We carried out a variety of analyses in which we controlled for characteristics of the doctor's diagnosis, sex, age, etc. All of these estimations give qualitatively the same results as the ones presented in columns (2 and 3) and (5 and 6), i.e. we get a non significant positive effect on net prescribed sick leave (i.e. increased hazard) and virtually no effect on gross prescribed sick leave.

\subsection{Actual sick leave}

Table 7 shows the corresponding estimates as in Table 6 but with actual sick leave as the dependent variable. The effect estimates show a statistically significant longer sickness leave in the treatment group of about 15 per cent lower hazard rate, both net and gross.

Table 7: Estimated effect (percentage) on actual sick leave (gross and net). 


\begin{tabular}{lrrrrrr}
\hline & $(1)$ & $\begin{array}{c}(2) \\
\text { Net }\end{array}$ & $(3)$ & \multicolumn{1}{c}{$(4)$} & \multicolumn{1}{c}{$(5)$} & $(6)$ \\
& & & & Gross & \\
\hline Effect & -0.154 & -0.141 & -0.117 & -0.185 & -0.171 & -0.157 \\
Standard Error & 0.056 & 0.056 & 0.059 & 0.056 & 0.056 & 0.059 \\
(p-value) & 0.006 & 0.012 & 0.047 & 0.001 & 0.002 & 0.008 \\
Historical sick & No & Yes & Yes & No & Yes & Yes \\
leave & No & No & Yes & No & No & Yes \\
Stratified by county & No & & & & &
\end{tabular}

Note: Estimates of Cox regression models with a "partial maximum likelihood" estimator.

We carried out a variety of analyses in which we controlled for diagnoses, sex, age, doctor's sex, etc. All of these estimations give qualitatively the same results as presented in columns (3) and (6). ${ }^{16}$

One problem with our study is that we have a limited amount (approximately 50 per cent) of the medical certificates that was produced during the period of the experiment. This could potentially have created a selected sample and lead to incorrect inference. In the sensitivity analysis in section 4.1, we found no sample selection problem. However, when we estimate the effect on actual sick leave we can neglect the sample selection problem by, simply, estimating the effect for all sick absence spells in the municipalities during the experiment period. Hence if we also find an effect using this sample, this provides a stronger support that there is no sample selection problem with the medical certificates.

The results (equivalent to Table 7) for this population are given in panel A in Table 8. This shows that impact estimates are statistically significant but that the effect is slightly lower for this population than for the population for which we have the medical certificates. The analysis comprises all sick leave spells, i.e. also sick leave granted by institutions other than health centres (i.e. hospitals and private doctors). Since many of the individuals on sick leave in the treatment municipalities were not subject to direct treatment, a slightly lower effect estimate is to be expected. The result is therefore not an indication of a selection problem.

As a further sensitivity analysis, we do the analysis in the same way but with data for the same period a year before the experiment was conducted. Since no experiments were carried out at this time, we expect no statistically significant effects. The results of this analysis are displayed in panel B of Table 8. These estimates are as expected not statistically significant.

\footnotetext{
${ }^{16}$ For reasons of space, the results of this additional analysis are not presented.
} 
Table 8 : Estimated effect (percentage) on actual sick leave (gross and net) for all individuals in the municipalities.

\begin{tabular}{|c|c|c|c|c|c|c|}
\hline & (1) & $(2)$ & (3) & (4) & $(5)$ & (6) \\
\hline & \multicolumn{3}{|c|}{ Net } & \multicolumn{3}{|c|}{ Gross } \\
\hline & \multicolumn{6}{|c|}{ A: Experiment-period ${ }^{\&}$} \\
\hline Effect & -0.094 & -0.070 & -0.073 & -0.096 & -0.074 & -0.079 \\
\hline Standard Error & 0.017 & 0.017 & 0.018 & 0.017 & 0.017 & 0.018 \\
\hline p-value & 0.000 & 0.000 & 0.000 & 0.000 & 0.000 & 0.000 \\
\hline \multirow[t]{2}{*}{ Number of individuals } & \multicolumn{6}{|c|}{20,280} \\
\hline & \multicolumn{6}{|c|}{ B: One year prior to the experiment ${ }^{\#}$} \\
\hline Effect & -0.021 & -0.013 & -0.026 & -0.023 & -0.013 & -0.027 \\
\hline Standard Error & 0.017 & 0.017 & 0.017 & 0.017 & 0.017 & 0.017 \\
\hline $\mathrm{p}$-value & 0.201 & 0.443 & 0.128 & 0.172 & 0.422 & 0.111 \\
\hline Number of individuals & \multicolumn{6}{|c|}{23,374} \\
\hline Historical sick leave & No & Yes & Yes & No & Yes & Yes \\
\hline Stratified on county & No & No & Yes & No & No & Yes \\
\hline
\end{tabular}

\section{Discussion and further analysis}

We find that the letter about increased monitoring affects the 25 per cent parttime sick leave: both prescribed sick leave and the actual sick leave. Overall, we find no effect on the number of gross prescribed sick leave, but the actual sick leave (gross and net) increases.

It has previously been shown (Palmer et al., 2008) that the net median time for those with 25 per cent work inability is significantly longer than the net median time with higher degrees of work inabilities. If this correlation is causal then it could explain why the letter extends the actual sick leave: the letter induces the doctors to prescribe more 25 per cent work inability which in turn prolongs actual sick leave. That the effect on duration is only visible in the actual sick leave and not in the prescribed sick leave can be explained by the fact that we only study the certificates issued during a limited time period. We do not, however, believe that the increase in the prescribed 25 per cent work inability can explain the entire increase in actual sick leave. 
A previous study by Johansson and Nilsson (2008) found that a request for completion of a medical certificate extends the number of days by 22 on average or by 30 per cent. The reason for this effect may be that the request for completion can delay rehabilitation and/or delay adjustment of the workplace etc. At worst, it also acts as a stress element for the insured, which can worsen the sickness and thus prolong the period of sick leave. Since we have information a certificate completed we can study the effect. The result from this analysis is that the notification letter increased the completion requirement by 4 percentage points on average or by 40 percent. ${ }^{17}$ Taking the results from Johansson and Nilsson of a 30 per cent extension ${ }^{18}$ of sick leave from the completion, this would mean that sick leave should be extended by about 1.2 per cent $(0.30 * 0.04)$ due to the notification letter. So a request for completion in itself explains only a small part of the overall effect of an extension of about 10 per cent.

\subsection{New medical certificates}

In Goine et al. (2009) the quality of 481 (240/241: treatment/control) new medical certificates was analysed. Two experienced insurance doctors, independently of each other, assessed these new certificates. The insurance doctors were to assess whether the information on the certificates was sufficient. The results of the study show significantly lower quality of the medical certificates among the treated than among the controls. This result was unexpected given that the message in the letter was that the SSIA required more complete information to avoid the need for supplementary information (completion). Since the effect from the letter on actual sickness absence and recommended absence are very similar to the total sample this, hence, implies that this difference in quality for this sub-sample is most likely informative about the process. ${ }^{19}$

Thus, the notification letter led to inferior quality of medical certificates, increased sick leave, increased granting of part-time sick leave and an increase

\footnotetext{
${ }^{17}$ See http://ucls.nek.uu.se/working\%20papers/wp20104ucls.doc.pdf for details. The average of all medical certificates in our sample sent for completion is 10.4 per cent.

${ }^{18} \mathrm{We}$ also estimated here (using Cox regressions and stratification on certificate length and diagnosis) the effect of a request for completion on sick leave (gross). The result (p-value $<0.05$ ) is approximately a 20 per cent increase in sick leave due to the request for completion.

${ }^{19}$ The result from the estimations are given in http://ucls.nek.uu.se/working\%20papers/wp20104ucls.doc.pdf.
} 
in 25 per cent part-time sick level. The first two effects are very surprising. Why would the quality of the medical certificates decrease and why would the sick leave increase when the SSIA notifies of increased monitoring?

One explanation could be that the increased effort from the SSIA can be a substitute, not a complement, to the increased effort from the doctors. This means that doctors react by taking less effort to act as a gatekeeper when the SSIA informs them that the SSIA will, for a limited period, take more effort in examining the medical certificates.

It is, however, also possible that the letter actually led to increased effort in assessing the patients' work capacity among the doctors, and that this increased the doctors' time spent with their patients. To write an accurate medical certificate is probably demanding with the tight time constraints that doctors face. And with more energy devoted to meeting and understanding the patient's complex situation, it is not unreasonable that this may come at the expense of quality of the certificates.

Another possibility is that the doctors may be more afraid of writing a "wrong" certificate. This implies that general practitioners may refer patients to specialists more often among the treated and that they may see the certificate as a temporary diagnosis pending the analysis by the specialist. In Sweden there is often a (long) waiting time for the patients to meet with the specialist. This explanation would, hence explain both the decrease in quality of the certificates and also the increase in length of sick spells.

\section{Conclusions}

Based on a randomised experiment we estimate effects of information about tightened monitoring of the medical certificates issued by doctors. We investigate both how the prescribed sick leave in the medical certificate is affected but also how the actual sick leave is affected. The randomised experiment is performed at the municipality level in the autumn of 2007. A letter was sent to medical centres to the treatment municipalities in which it was stated that the medical centre was targeted by the Swedish Social Insurance Agency (SSIA) for specific monitoring of the medical certificates.

The study shows that notification of increased monitoring affects both the level of prescribed sick leave and actual sick leave: the letter increases the prescribed sick leave and actual sick leave with a 25 per cent work inability and reduced (potentially) full time (i.e., a 100 per cent work inability) prescribed 
sick leave. In contrast, it does not seem to affect the total length of the gross days prescribed by doctors. We also find that the letter increased the actual sick leave (both net and gross).

The SSIA has no way to sanction doctors who write medical certificates that are low in quality. A reasonable assumption would be that notification of increased monitoring would have little or no impact on how doctors write certificates. This is also the result that occurs when we study the effects on the prescribed sick leave in the medical certificates. However, it is difficult to explain why actual sick leave would increase. In Goine et al. (2009) an analysis of the quality of new medical certificates showed that the quality of the medical certificate was worse in the treatment municipalities than among control municipalities. This result is also difficult to explain. If, however, it means that low quality medical certificates lead to longer sick leave, the two results are at least internally consistent.

Certificates that are of poor quality are more often referred back for supplementary information and completion to the issuing doctor (Johansson and Nilsson, 2008). Also, in our study it was also revealed that medical certificates are sent back for completion to the issuing doctor more often in the medical centres included in the treatment group. It has previously been shown (Johansson and Nilsson, 2008) that the requirement for completion also prolongs the length of sick leave. In this study we have shown, however, that the requirement for completion could explain only a marginal increase in sick leave.

We discuss three different reasons for sick leave being longer due to the notification letter about increased controls: (i) doctors reduce their efforts as gatekeeper when the SSIA state that they increase their efforts to be gatekeeper; (ii) the efforts by the doctor to diagnose the patient increases, leaving less time to write the medical certificate and also making it more complicated to write; (iii) the doctors refer patients to specialists more often than previously - this in turn reduces the importance of the first medical certificate.

These explanations are not mutually exclusive and are certainly not comprehensive. More research into the doctor's role in the process is of large interest. There are studies that suggest that sick leave is largely controlled by the individual's own motivation (Arrelöv, 2006 and Englund, 2008). If this fully applies, it is not possible to reduce sick leave by notifying doctors of increased monitoring. 
In our study a correct medical certificate, however, seems to reduce actual sick leave, as also shown in Johansson and Nilsson (2008). If it is in the interest of society to reduce sick leave there may be a need for incentives for doctors to fill out certificates properly. Properly completed medical certificates are also an important prerequisite for the judicious treatment of an individual's entitlement to sickness benefit. 


\section{References}

Arrelöv B (2006). Läkarna i sjukskrivningsprocessen i SKA Projektet: Sjukförsäkring, kulturer och attityder. Edward Palmer (red), Analyserar 2006:16, Stockholm: Försäkringskassan.

Englund L ( 2008). Hur har distriktsläkares sjukskrivningspraxis förändrats under 11 år? Resultat av tre praxisundersökningar bland distriktsläkare i ett svenskt landsting åren 1996, 2001 och 2007. Arbetsrapport: Centrum för Klinisk Forskning Dalarna, Falun.

SSIA (2004). Sjukpenning och samordnad rehabilitering. Försäkringskassans Vägledning.

SSIA (2007). Nej till sjukpenning vad hände sen? Försäkringskassan Analyserar 2007:1.

SSIA (2007) "De gemensamma metoderna i sjukförsäkringen - hur blev det?". Försäkringskassan redovisar 2007:8.

Goine H, P Engström, E Palmer och E Söderberg (2009). IFAU Rapport 2009:14.

Henrekson, M and M Persson (2004) The Effect on Sick Leave of Changes in the Sickness Insurance System, Journal of Labor Economics, Vol. 22, No.1, 2004.

Hesselius P, P Johansson och L Larsson (2006). Hur påverkar kravet på läkarintyg sjukfrånvaron? Erfarenheter från ett socialt experiment. Ekonomisk Debatt 2, 5-16.

Hesselius P, P Johansson and Nilsson, P. (2009). Sick of your colleagues's absence?", Journal of European Economic Association 7 (2-3), 1-12.

Johansson, P och M Nilsson (2008). Finns det något samband mellan sjukintygets kvalitet och sjukfrånvaro. IFAU Rapport 2008:27. 
Johansson, P and M Palme (1996). Do Economic Incentives Affect Worker Absence? Empirical Evidence Using Swedish Data. Journal of Public Economics, 59, 195-218.

Johansson P and M Palme (2002). Assessing the Effect of a Compulsory Sickness Insurance on Worker Absenteeism. Journal of Human Resources, 37, 381-409.

Johansson, P and M Palme (2005). Moral hazard and sickness insurance. Journal of Public Economics, 89, 1879-1890.

Lindahl, E. (2008). Empirical studies of public policies within the primary school and the sickness insurance Uppsala Economic studies 111.

Lindbeck, A, M Palme and M Persson (2007). Social Interaction and Sickness Absence, Industrial Research Institute (IFN), Working Paper No 725.

OECD (2009). Sickness, Disability and Work: Breaking the Barriers Sweden: Will the Recent Reforms Make it?

Palmer, E. (2006). (red.) SKA Projektet: Sjukförsäkring, kulturer och attityder. Analyserar 2006:16, Stockholm: Försäkringskassan.

Palmer, E Svensson I, Tirmén, P Österlund, N (2008). Sjukförmåner på deltid i L. Hartman (red.) Välfärd på deltid. Stockholm, SNS Förlag. 


\title{
Appendix: Letter to Health Centres
}

\author{
Health Centre/Head of Primary Care \\ XXX XXXXXXX \\ Sveagatan 99 \\ 99999 Småstad
}

Follow-up on medical certificates and control of the right to sickness benefit

Everyone with responsibilities for providing information in connection with sick leave has a lot to gain by getting it right from the start. During the autumn, as part of ensuring that the correct payments are made, various specific control efforts will be implemented within the sickness insurance. Behind this initiative there is an explicit request from the Government.

Based on previous experience between a third and a half of medical certificates submitted to the SSIA provide an inadequate picture of the patient's illness and how it affects the patient's capacity for work. This causes a huge requirement for supplementary information and completion from the doctor who wrote the certificate, which in turn puts a burden on health care. This means it takes longer for the SSIA to handle the case and may mean that payments to the individual are delayed or withheld.

For this reason the SSIA will conduct a systematic follow-up of all the medical certificates/doctor's certificates during the period from 27 August until 30 September 2007 in a randomly selected number of municipalities. XXXXX's health centre/primary care unit will be included in this follow-up.

The SSIA is doing this with the aim of implementing the proper verification of entitlement to sickness benefit on the basis of information supplied by the insured, the employer and the doctor granting the certificate during the period specified above.

One consequence of this follow-up on medical certificates and the verification of entitlement to sickness benefit is that the SSIA staff may contact the doctor granting the certificate on more occasions than usual to request supplementary information and completion. We therefore hope that all doctors who grant medical certificates at the health centre/primary care unit are made aware of this letter.

For more information about this follow-up effort, please contact XXXX XXXXX at the SSIA in Z County (direct telephone: xxxxxxx).

Yours sincerely

XXXXX XXXXXXX 